\title{
History of Myocardial Infarction Within 6 Months
}

National Cancer Institute

\section{Source}

National Cancer Institute. History of Myocardial Infarction Within 6 Months. NCI

Thesaurus. Code C17849.

An event in a personal medical history indicating that a myocardial infartion has occurred during the previous 6 months. 